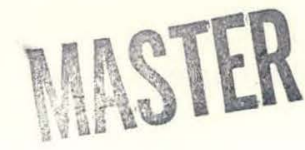

EFFECTS OF OPERATING VARIABLES ON PEAK SHAPE IN GEL PERMEATION CHROMATOGRAPHY

\author{
Joseph L. Glajch, Doris C. Warren, Mary A. Kaiser, and L. B. Rogers* \\ Department of Chemistry \\ University of Georgia \\ Athens, Georgia 30602
}

September 1978

This report was prepared as an account of work
sponsored by the United States Government. Neither the
United States nor the United States Department of
Energy, nor any of their employees, nor any of their
contractors, subcontractors, or their employees, makes
any warranty, express or implied, or assumes any legal
liability or responsibility for the accuracy, completeness
or usefulness of any information, apparatus, product or
process disclosed, or represents that its use would not
infringe privately owned rights.

PREPARED FOR THE

U.S. DEPARTMENT OF ENERGY

UNDER CONTRACT EY-76-S-09-0854 


\section{DISCLAIMER}

This report was prepared as an account of work sponsored by an agency of the United States Government. Neither the United States Government nor any agency Thereof, nor any of their employees, makes any warranty, express or implied, or assumes any legal liability or responsibility for the accuracy, completeness, or usefulness of any information, apparatus, product, or process disclosed, or represents that its use would not infringe privately owned rights. Reference herein to any specific commercial product, process, or service by trade name, trademark, manufacturer, or otherwise does not necessarily constitute or imply its endorsement, recommendation, or favoring by the United States Government or any agency thereof. The views and opinions of authors expressed herein do not necessarily state or reflect those of the United States Government or any agency thereof. 


\section{DISCLAIMER}

Portions of this document may be illegible in electronic image products. Images are produced from the best available original document. 
"This report was prepared as an account of work sponsored by the United States Government. Neither the United States nor the United States Department of Energy, nor any of their employees, nor any of their contractors, subcontractors, or their employees, makes any warranty, expressed or implied, or assumes any legal liability or responsibility for the accuracy, completeness or usefulness of any information, apparatus, product or process disclosed, or represents that its use would not infringe privately-owned rights." 


\title{
EFFECTS OF OPERATING VARIABLES ON PEAK SHAPE IN \\ GEL PERMEATION CHROMATOGRAPHY
}

\author{
Joseph L. Glajch, Doris C. Warren', Mary A. Kaiser², and L. B. Rogers* \\ Department of Chemistry \\ University of Georgia \\ Athens, Georgia 30602
}

\begin{abstract}
The effects of flow rate, solute molecular weight, added dead volume, and different detectors on peak shape in a gel permeation chromatographic (GPC) system have been studied. Toluene and three monodispersed polystyrenes, having nominal molecular weights of $37,000,110,000$, and 233,000 were examined using the second moment, the standard deviation of the Gaussian component of the peak $(\sigma)$, and the exponential tailing function $(\tau)$. Detector effects reflected primarily the cell volume and not the additional dead volume that included its connecting tubing. The addition of $25 \mu \mathrm{L}$ of narrow-bore tubing between the injector and the column slightly decreased the second moment of the peak. The use of $\sigma$ values, in addition to the second moment, also allowed confirmation of previous predictions based on computer simulation studies showing peak spreading as a function of molecular weight.
\end{abstract}

'Present Address: Department of Chemistry, Houston Baptist University, 7502 Fondren Road, Houston, Texas 77074.

2Present Address: Central Research and Development Department, E. I . DuPont de Nemours and Company, Incorporated, Wilmington, Delaware 19898. 


\section{INTRODUCTION}

The analysis of peak shape in chromatography, using both simulated and real data, continues to receive a great deal of attention as data acquisition and reduction techniques become more sophisticated. A dramatic increase in the use of laboratory minicomputers and microprocessor systems in conjunction with chromatographic apparatus allows the analyst to collect easily the digitized chromatograms which can then be used in peak shape studies.

Although a Gaussian probability function is the simplest approach (and for a first approximation of system behavior, the most widely used), an exponentially modified Gaussian is now the model preferred by many chemists for describing the actual peak shapes. Sternberg (1) was one of the first investigators to point out the causes and problems of asymmetric peaks in gas chromatography. Grushka (2) and others (3-7) have extended the characterization of these peaks. The exponentially modified Gaussian can be described by

$$
f(t)=\frac{N}{\tau_{\sigma} \sqrt{2 \pi}} \int_{0}^{\infty} \exp \left[\frac{-\left(t-t_{R}-t^{\prime}\right)^{2}}{2 \sigma^{2}}\right] \exp \left[\frac{-t^{\prime}}{\tau}\right] \underline{d t}
$$

where $N$ is the normalized peak amplitude, $\sigma$ is the standard deviation of the Gaussian, $\tau$ is the exponential decay time constant, $t_{R}$ is the center of gravity of the Gaussian, and $t^{\prime}$ is a dummy variable of integration. The decay constant, $\tau$, can be due to one effect or a combination of a number of independent effects, such as detector response (linearity and volume), dead volume, recorder response time, and other extra-column contributions. In the case of a combination of independent effects, the overall decay constant, $\tau_{T}$, would result from the 
individual constants as expressed by

$$
\tau_{T}=\left(\tau_{1}{ }^{2}+\tau_{2}^{2}+\tau_{3}^{2}+\ldots+\tau_{n}^{2}\right)^{1 / 2}
$$

since moment theory predicts $\tau_{T}{ }^{2}$ to be the sum of the squares of the individual $\tau$ values.

In a pure Gaussian system, the zeroth moment is the peak area, the first moment is $t_{R^{\prime}}$ the second central moment is $\sigma^{2}$, the third central moment is zero, and the fourth central moment is $3 \sigma^{4}$. For an exponentially modified Gaussian, the zeroth moment is still the peak area and the next four moments can be expressed as

$$
\begin{aligned}
& \underline{M_{1}}=\underline{I R}^{t}+\tau \\
& \underline{M_{2}}=\sigma^{2}+\tau^{2} \\
& \underline{M_{3}}=2 \tau^{3} \\
& \underline{M_{4}}=3 \sigma^{4}+\sigma_{\sigma}{ }^{2} \tau^{2}+9 \tau^{4}
\end{aligned}
$$

In the examination of real data, the analyst would prefer to deconvolute the digitized data to extract single values for $\sigma$ and $\tau$. Yau (8) has recently proposed such a method, and Pauls and Rogers (9) have used this for the examination of a gas chromatographic system. In addition, Kirkland, Yau, Stoklosa, and Dilks (10) have studied extra-column effects in high-performance liquid chromatography with particular emphasis on the use of this alogorithm for plate-count calculations. 
In the present study, the effects of operating parameters on peak shape in a gel permeation chromatographic (GPC) system have been examined. Initially, the effects of solute retention volume (as reflected by nominal molecular weight) and flow rate on the peak shape were studied. Later, we were interested in the influence on peak shape of system dead volume, especially dead volume in the connecting tubing and in the detector.

The use of the $\sigma-\tau$ algorithm to characterize these peak shapes has been compared to the use of only the second moment. The second moment is a measure of the peak width and can be affected by either $\sigma$ or $\tau$, so the algorithm can give complementary information to that contained in $M_{2}$ alone. Their values better correlate with theoretical predictions based on computer simulations of GPC.

Finally, these studies suggest how the selection of analytical conditions, including the design of equipment, might be used to improve the chromatographic information obtained.

\section{EXPERIMENTAL}

\section{Reagents}

The mobile phase and solvent used to dissolve the solutes was a 90:10 mixture of chloroform and isopropanol (Baker Analyzed Reagents, J. T. Baker Co., Phillipsburgh, NJ). Although that mixture is not the solvent of choice for determinations of molecular weights of polystyrenes, it was used along with the polystyrene standards, in an earlier study (11) involving coal tars and heavy ends of petroleum distillates. The isopropanol was used to minimize solute adsorption on the stationary phase and limit the separation mechanism to size exclusion. 
Toluene (Baker Analyzed Reagent) was used as the totally permeating species with a sample concentration of $10 \mathrm{mg} / \mathrm{mL}$. Three polystyrene solutes (all with $M_{w} M_{n}<1.06$ ) were obtained from Pressure Chemical Co. (Pittsburgh, PA): $37,000 \mathrm{MW}, 110,000 \mathrm{MW}$, and $233,000 \mathrm{MW}$ and used at concentrations of 10,5 , and $2.5 \mathrm{mg} / \mathrm{mL}$, respectively. These concentrations were consistent with the solubilities of each of these in the chloroform-isopropanol solvent. The fact that these "monodisperse" polystyrenes were known to be a mixture of oligomeric species was not of particular importance, since the effects of various parameters on peak shape were explored only in a relative sense.

Two columns $(20 \mathrm{~cm} \times 6.35 \mathrm{~mm}$ i.d.) were slurry packed with $10 \mu \mathrm{m}$ particles of LiChrospher TM (EM Laboratories, Inc., Elmsford, NY) and connected in series by low dead volume tubing and fittings. A $0.5 \mu \mathrm{m}$ frit was used at each end of each column to retain the packing. The first column contained SI 100 and the second column SI 500 - both are silica packings with controlled-pore diameters.

\section{Apparatus}

The gel permeation chromatographic (GPC) solvent delivery system incorporated a Milton-Roy 196-31 pump (Milton Roy Co., Riviera Beach, FL), which had an operating range of $0-1000 \mathrm{psi}(0-6.9 \mathrm{MPa})$. To minimize pulse effects in the system, a $300 \mathrm{~mL}$ cylinder, a $1.3 \mathrm{~m}$ coil of $0.25 \mathrm{~mm} \mathrm{i.d.} \mathrm{tubing,} \mathrm{and} \mathrm{two}$ pressure regulator gauges were installed between the pump and sampling valve. The six-port autoinjector valve (Valco Instruments Co., Inc., Houston, TX) was air-actuated and computer controlled. All connecting tubing, columns, cylinder, and injector parts were made of 316 stainless steel. 
The three detectors used were an LDC DuoMonitor ultraviolet absorbance detector (Laboratory. Data Control, Riviera Beach, FL), a Perkin-Elmer LC-55 ultraviolet absorbance detector (Perkin-Elmer Corp., Norwalk, CT), and an LDC Refractomonitor refractive index detector (Laboratory Data Control). A minimum amount of $0.25 \mathrm{~mm}$ i.d. tubing was used to connect the columns to the defectors. The UV measurements were made at $254 \mathrm{~nm}$.

The system was operated by a PDP 11-20 minicomputer system (Digital Equipment Corp., Maynard, MA) programmed in real-time BASIC using an Anscan analog-to-digital converter (Beckman Instruments, Inc., Fullerton, CA): The PDP 11-20 was also used to generate the simulated peaks using equation 1 and perform the data reduction using a modified version of Yau's algorithm.

\section{Procedures}

Each combination of solute, flow rate, detector, and added dead volume was automatically run by computer-controlled instrumentation for data acquisition. The flow rates were measured using a volumetric pipet flow meter connected at the outlet of the detectors. The pre-column dead volume was added directly between the injector valve and the inlet of the first column, while the postcolumn dead volume was inserted directly at the outlet of the second column. The long, narrow-bore tubing was $0.25 \mathrm{~mm}$ i.d. while the short, wide-bore tubing was $0.76 \mathrm{~mm} i . d$. The sample solution was automatically flushed, using a homemade system, through the $10 \mu \mathrm{L}$ sample loop of the injector for 10 seconds and then injected. Data were taken only in the region of the peak, and a data density of two points/second was used. Depending on the peak width, either 510 or 756 data points were collected, following which the sample solution was again flushed through the sample loop and the entire cycle repeated. Eleven 
runs were made under each set of conditions to determine reproducibility. Some replicate sets of runs were also done to check long-term reproducibility. For example, the $233,000 \mathrm{MW}$ polystyrene on the DuoMonitor with a flow rate of $0.6 \mathrm{~mL} / \mathrm{min}$ gave $\sigma=51.0 \mu \mathrm{L}, \tau=274 \mu \mathrm{L}$, and $\mathrm{M}_{2}=77.9 \times 10^{-3} \mu \mathrm{L}^{2}$ for one set of runs. On a different day the values were $52.1 \mu \mathrm{L}, 265 \mu \mathrm{L}$, and $79.5 \times 10^{-3} \mu \mathrm{L}^{2}$, respectively.

\section{RESULTS}

\section{Preliminary Study}

Simulations. The use of the algorithm described by $\mathrm{Yau}(8)$ requires that values first be obtained for both the zeroth and first moments. In past work (9), a threshold at $1 \%$ of peak maximum has been used. However, in addition to the errors in the moments that Chesler and Cram (6) have already pointed out as a result of using only a threshold, we have discovered even greater errors for calculations of the $\sigma$ and $\tau$ values.

The data in Table I point out that using all 480 points for the simulated peaks (720 points for the $\sigma=20, \tau=40$ peak), values of $M_{1}$, $\sigma$, and $\tau$ were in excellent agreement with the actual input values. However, use of the $1 \%$ threshold for the initial calculations of moments introduced errors in the final values, particularly those for $\tau$. Our iterative technique for moment calculations involved using two $1 \%$ thresholds only to get a first approximation of $M_{1}, \sigma$, and $\tau$. Then, the threshold on the front of the peak, $L_{L}$ in Figure 1, was retained for the iteration, but a new right limit, $\underline{R_{2}}$ was determined using the formula

$$
\underline{R_{2}}=M_{1}+(\sigma+\tau) \frac{\left(M_{1}-\underline{L_{1}}\right)}{\sigma}
$$


where $\sigma$ and $\tau$ are the values of the standard deviation and the decay constant determined from the first approximation using two $1 \%$ thresholds. Using this formula, the iterative technique allows for the use of more points when they are needed (for peaks with a large tail), while limiting the "extra" points for peaks having minimal tailing. In principle, the iteration could be repeated to refine the final limit values, but we found one iteration to be sufficient to attain accurate $M_{1}, \sigma$, and $\tau$ values as shown in Table 1 . The improvement was particularly noticeable in the $\tau$ values. When $L_{1}$ was chosen to be $2 \%$ or $5 \%$ of the peak maximum, the accuracies of the final values were not as good as those when the $1 \%$ limit was used.

Although all of the data points can be used in the case of a simulated peak, a consistent analysis is needed in the case of real chromatograms. Using a $1 \%$ threshold for the left limit and the proposed iterative technique for the right limit, this can be achieved. A data density of at least 10 points per $\sigma$ unit was used, consistent with an earlier finding that this was needed to insure accurate results (9).

\section{Gel Permeation Study}

Our primary interest in the GPC study was to examine dead volume effects due to both connecting tubing and detector cell. However, we first needed to evaluate the effects of flow rate and solute to insure that subsequent studies would not be undertaken under experimental conditions that would give anomalous results. In the process, interesting findings were made which, using the results of the $\sigma-\tau$ analysis, permitted correlations to be made with earlier theoretical predictions. 
Effect of Flow Rate. A study of the effect of peak broadening as a function of flow rate indicated the importance of presenting our data with separate $\sigma$ and $\tau$ contributions, in addition to a total second moment $\left(\sigma^{2}+\tau^{2}\right)$ analysis. As shown in Table II, the values of the latter term seemed to increase slightly with faster flow rates, but the scatter in the data would not allow for a definitive conclusion to that effect.

The change in $\sigma$ values was clearer, however, particularly in the case of the polystyrenes, where a complex variation of $\tau$ with respect to flow would obscure the $\sigma$ effect if only a second moment analysis was used. These $\sigma$ values, which show only a slight increase as a function of increasing flow rate, agree with the computer simulations of gel permeation chromatography of Ouano and Barker (12) for their "equilibrium zone." In essence, our data are in the range of flow rate where diffusion into and out of the stationary phase is not a significant factor in the variance. Instead, an equilibrium between the stationary phase and the solutes exists. Using their equations and the operating parameters in our experimental system, we calculated that we were just below the flow rate range where a transition would occur toward what they termed a "diffusion zone" in a plot of variance versus flow rate. In that zone, the logarithm of the variance should increase linearly as a function of the logarithm of the flow rate.

It should also be mentioned that in our work the volumes of both the first moments and peak maxima remained constant within experimental error over the range of flow rate examined. This agrees with the negligible to slight decreases in the volumes for the peak maxima with increasing flow that Ouano and Barker predicted. Had we used flows from $2-8 \mathrm{~mL} / \mathrm{min}$, the differences could have been significant. 
Effect of Solutes. The change of $\mathrm{M}_{2}$ as a function of the molecular weight of the solute at a given flow did not follow a continuous pattern for our data, as shown in Table II. The peak was broader for the 37,000 MW (37K) than for toluene and broader for the $233,000 \mathrm{MW}(233 \mathrm{~K})$ than for the $110,000 \mathrm{MW}$ (110K); but the peak actually narrowed in the transition from $37,000 \mathrm{MW}$ to $110,000 \mathrm{MW}$. At first glance, this effect appeared unusual; however, when separate values of $\sigma$ and $\tau$ were examined, consistency with previous work (12) was evident. Although the $\tau$ values follow a pattern similar to that of $\underline{M_{2}}$ for the series of four solutes, the $\sigma$ values reached a maximum at the $37,000 \mathrm{MW}$ species. This is the same behavior previously simulated and observed by Ouano and Barker (12) for polystyrenes having a different set of molecular weights when using a packing having an exclusion limit of 10,000. Such a maximum in the variance as a function of molecular weight was attributed to two opposing parameters--the smaller diffusion coefficient with increasing molecular weight, which increased band broadening, and the thinner diffusion layer with increasing molecular weight, which decreased band broadening once the column exclusion limit had been exceeded. Since the exclusion limits of our two columns were 60,000 and 400,000, respectively, for the SI 100 and SI 500 columns, it is reasonable that the diffusion-layer thickness term might have begun to dominate once the exclusion limit of the SI 100 column had been exceeded.

It should be noted that in the subsequent studies of added dead volumes and detector cells, the comparison's were always based on the same solute for a given change in conditions.

Effects of Added Dead Volumes. The effect on the peak broadening of adding $25 \mu \mathrm{L}$ of dead volume to the system is shown in Table III. The most unusual aspect of this comparison can be seen with the addition of $25 \mu \mathrm{L}$ of 
long thin tubing in front of the column. The $\sigma$ decreased only in the case of the 37,000 MW species (and then only slightly), and the effect on the toluene peak was slight if it existed at all (3\% for $\tau$ and $4 \%$ for $\left.\underline{M}_{2}\right)$. However, the changes for the polystyrenes were all far outside of the limits of experimental error. An example is shown in Figure 2 and Table III using 37,000 MW polystyrene as the solute in a system both with and without added precolumn dead volume. Note in the table that a small amount of added dead volume before the column produced a larger second moment, while the same amount of added dead volume after the column resulted in smaller second moment. Note, too, that these effects were due primarily to increases in the $\tau$ values.

It has previously been shown (15) that the additional variance (in $\mathrm{mL}^{2}$ ) due to tubing in a GPC system follows a relationship

$$
\sigma_{\underline{v}}{ }^{2}=\frac{\pi \underline{r}^{4} \mid Q}{24 \underline{\underline{m}}}
$$

where $r$ is the radius of the tubing, 1 is the length of the tubing, $Q$ is the flow rate in $\mathrm{mL} / \mathrm{sec}$, and $\underline{D}_{\underline{m}}$ is the diffusivity of the solute in the mobile phase. Using a constant flow of $0.5 \mathrm{~mL} / \mathrm{min}$ with a tubing volume of $25 \mu \mathrm{L}$, Equation 8 reduces to

$$
\sigma_{\underline{v}}{ }^{2}=2.73 \times 10^{-2} \frac{\mathrm{r}^{2}}{\underline{\mathrm{D}}_{\underline{m}}}
$$

where $\sigma_{v}{ }^{2}$ is now expressed in units of $\mu L^{2} \times 10^{3}$ consistent with the data in Table III. According to Equation 9, the narrow-bore tubing will increase band broadening much less than the wide-bore tubing for a given volume, as other studies have already indicated (13-18). 
Another important parameter to be considered here, however, was the effect of $\underline{D}_{-}$on the variance. In normal liquid chromatography, the diffusivity values for small solutes, like toluene, are within the same order of magnitude (usually about $10^{-5} \mathrm{~cm}^{2} / \mathrm{sec}$ ). In the case of GPC of polystyrenes, $\underline{D}_{m}$ can vary over a few orders of magnitude (for example, $\underline{D}_{\underline{m}}$ for $233 \mathrm{~K}$ should be about $5 \times 10^{-7} \mathrm{~cm}^{2} / \mathrm{sec}$ ). This will have a significant effect on $\sigma_{\underline{v}}{ }^{2}$, especially under the conditions of our experimental work. The values in Table III show a significant effect on the $M_{2}$ values for the polystyrenes with the addition of dead volume, especially for the wide-bore tubing. Again, the effect on toluene was within the experimental uncertainty.

Even considering the results above, the decrease in $\underline{M}_{2}$ with narrow-bore pre-column tubing is surprising, especially since the effects on $\sigma$ and $\tau$ were offen irregular. However, the decrease in $\tau$ values with the narrow-bore tubing, as opposed to no added dead volume, is responsible for the decrease in $M_{2}$, thus causing the peaks to be more nearly Gaussian in the final analysis. It can be hypothesized that the extra $25 \mu \mathrm{L}$ reduced the pressure surge on the column due to the sampling valve and resulted in a more nearly symmetrical injection into the column. The recent suggestion of Kirkland et al. (10) of point-injection and their discussion of this technique as opposed to "normal" valve injection points out the broadening problems inherent in the latter case.

Effect of Volume of the Detector Cell. Finally, a comparison of the three different detectors, all of which had the U-shaped flow configuration, revealed a strong dependence of the second moment on the cell volume of the detector. Table IV shows that the refractive index detector was smaller than either UV detector in total dead volume (cell plus tubing). However, when 
considering the cell volume only, it was approximately the same as the LC-55 detector. As shown in Table V, these latter two detectors were clearly superior to the LDC DuoMonitor with respect to the second moment. Both $\sigma$ and $\tau$ were shown to affect these total values of $M_{2}$. For example, the decrease in $\tau$ was the dominant factor for the lower $M_{2}$ for the $233 \mathrm{~K}$ with the Refractomonitor (the $\sigma$ actually increased slightly). However, the decrease in $M_{2}$ for the $233 \mathrm{~K}$ for the LC -55 was due to both lower $\sigma$ and $\tau$ values.

The LC-55 and the DuoMonitor have approximately the same total dead volume but substantially different fractions in the cell and in the tubing. Tables IV and $V$ clearly indicated that the cell volume determined the extent of the band broadening (especially for $\tau$ ) rather than the connecting tubing. However, the tubing should be kept to a minimum for optimum results, as Scott and Kucera (15) have already demonstrated.

\section{DISCUSSION}

This study has demonstrated another advantage that results from using the $\sigma-\tau$ algorithm for peak shape analysis. In addition to the improvement in the precision of the calculated second moment $(8,9)$, we were able to confirm, using three polystyrene solutes, earlier theoretical predictions (14) concerning interacting effects of flow rate and molecular weight. In contrast, second moments were not useful in this regard. Although careful control of flow rate was not as important as molecular weight (diffusion coefficient) in the range we used, flow rate can be important in these types of analyses, particularly for polydispersed species. 
The present study has also served to confirm the importance of minimizing the cell volume of the defector. Our results suggest that the most efficient detector design would incorporate a very low volume cell, even at the expense of extra connecting tubing. In addition, all of the detectors in the present study had U-shaped configurations, so other flow patterns might give different results, as Lochmuller et al. (19) have indicated for gas chromatographic detector cells.

The general problem of obtaining a good injection was emphasized by the fact that the additional $25 \mu L$ of narrow-bore tubing between the injector and column led to a smaller second moment. Further study in this area should permit a better understanding of that result and might suggest how the effect could be optimized.

After our study had been completed, Kirkland et al. (10) recommended the use of screens instead of frits at the ends of columns. For those chromatographers who are using frits, we can report that clogging of the frits (and subsequent broadening of the peak) occasionally occurred very suddenly. Replacement by a new frit resulted in peak shapes consistent with those obtained using the original frit before it began to plug. 


\section{ACKNOWLEDGEMENTS}

We are grateful to W. W. Yau and Charles Lochmoller for stimulating discussions and to Morris Geffen and James Webb for help in the experimental work.

One of us (JLG) acknowledges the support of a Graduate Assistantship from the Graduate. School of the University of Georgia and another (DCW) acknowledges the National Science Foundation for summer support through Grant No. CHE 74-23610 AO2.

This work was supported in part by the U.S. Department of Energy through Contract $E(38-1)-854$. 


\section{REFERENCES}

1. J. C. Sternberg, Advances in Chromatography, Vol. 2, J. C. Giddings and R. A. Keller, eds., Marcel Dekker, New York, NY, (1966), p.205.

2. E. Grushka, Anal. Chem., 44, 1733 (1972).

3. H. M. Gladney, B. F. Dowden, and J. D. Swalen, Anal. Chem., 41, 883 (1969).

4. 1. G. McWilliam and H. C. Bolton, Anal. Chem., 4l, 1755 (1969).

5. A. H. Anderson, T. C. Gibb, and A. B. Littlewood, J. Chromatogr. Sci., $8,649(1970)$.

6. S. N. Chesler and S. P. Cram, Anal. Chem., 43, 1922 (1971).

7. O. Grubner, Anal. Chem., 43, 1934 (1977).

8. W. W. Yau, Anal. Chem., 49, 395 (1977).

9. R. E. Pauls and L. B. Rogers, Anal. Chem., 49, 625 (1977).

10. J. J. Kirkland, W. W. Yau, H. J. Stoklosa, and C. H. Dilks, Jr., J. Chromatogr. Sci., 15, 303 (1977).

11. J. C. Hodgin, M. A. Kaiser, J. A. Lubkowitz, and L. B. Rogers, J. Chromatogr., 135, 514 (1977).

12. A. Ouano and J. A. Biesenberger, J. Chromatogr., 55, 145 (1971).

13. J. A. Biesenberger and A. Ouano, J.Appl. Polym. Sci., 14, 471 (1970).

14. J. A. Biesenberger and A. Ouano, J. Appl. Polym. Sci., 14, 483 (1970).

15. A. C. Ouano and J. A. Barker, Sep. Sci., 8(6), 673 (1973).

16. R. P. W. Scott and P. Kucera, J. Chromatogr. Sci., 9, 641 (1971).

17. F.W. Billmeyer, Jr., G.W. Johnson, and R. N. Kelley, J. Chromatogr., 34, 316 (1968).

18. F. W. Billmeyer, Jr. and R. N. Kelley, J. Chromatogr., 34, 322 (1968).

19. C. H. Lochmetler, B. M. Gordon, A. E. Lawson, and R. J. Mathieu, J. Chromatogr. Sci., 15, 285 (1977). 
Figure 1. Simulated Peak $\sigma=10, \tau=20$ points

$L_{1}$ - left limit for moment calculations.

$R_{1}$ - initial right limit for moment calculations

$R_{2}$ - final right limit for moment calculations

Figure 2. Comparison of peak shape with and without precolumn added dead volume. 37,000 MW polystyrene solute on LDC DuoMonitor. Flow rate $0.5 \mathrm{~mL} / \mathrm{min}$. 
TABLE 1

COMPARISON OF THREE METHODS FOR CALCULATING $\sigma$ and $\tau$

INPUT

\begin{tabular}{|c|c|c|c|c|c|c|c|c|c|c|}
\hline & $\tau$ & ${ }^{\sigma_{A L L}}{ }^{a}$ & $\sigma_{1 \%}$ & $\sigma_{\text {ITER }} b$ & ${ }^{\tau}{ }_{A L L}{ }^{a}$ & $\tau_{1 \%}$ & $T_{\text {ITER }}^{b}$ & $M_{I A L L}{ }^{a}$ & $M_{11 \%}$ & $M_{I I T E R}^{b}$ \\
\hline 5 & 0 & 5.03 & 5.01 & 5.03 & 0.06 & -0.19 & -0.13 & 100.00 & 100.00 & 100.00 \\
\hline 5 & 10 & 5.01 & 5.05 & 5.00 & 10.01 & 9.61 & 9.95 & 100.01 & 99.77 & 99.98 \\
\hline 5 & 25 & 5.03 & 5.08 & 5.00 & 24.83 & 24.00 & 24.98 & 99.87 & 99.19 & 99.99 \\
\hline 10 & 10 & 10.00 & 10.03 & 10.00 & 10.01 & 9.61 & 9.97 & 100.01 & 99.85 & 100.00 \\
\hline 10 & 20 & 10.02 & 10.07 & 9.97 & 19.94 & 19.23 & 19.90 & 99.97 & 99.53 & 99.95 \\
\hline 20 & 40 & 20.00 & 20.10 & 19.91 & 40.00 & 38.42 & 39.79 & 200.00 & 199.03 & 199.89 \\
\hline
\end{tabular}

a. ALL - Using all data points.

b. ITER - Using iterative procedure. 
TABLE $\|$

\section{EFFECT OF FLOW RATE ON PEAK CHARACTERISTICS}

DuoMonitor Detector at $254 \mathrm{~nm}$

\begin{tabular}{|c|c|c|c|c|c|c|c|c|c|c|c|c|}
\hline \multirow{2}{*}{$\begin{array}{l}\text { Flow Rate } \\
\mathrm{mL} / \mathrm{min}\end{array}$} & \multicolumn{4}{|c|}{$\sigma(\mu L)$} & \multicolumn{4}{|c|}{$\tau(\mu \mathrm{L})$} & \multicolumn{4}{|c|}{$M_{2}\left(\mu L^{2} \times 10^{3}\right)$} \\
\hline & Toluene & $37 K$ & $110 \mathrm{~K}$ & $233 \mathrm{~K}$ & Tolvene & $37 K$ & $110 \mathrm{~K}$ & $233 K$ & Tolvene & $37 K$ & I10K & $233 K$ \\
\hline 0.5 & $56.7(0.8)^{a}$ & $106(2.1)$ & $82.0(3.5)$ & $50.4(1.5)$ & $218(3)$ & $234(3)$ & $214(12)$ & $288(9)$ & $50.9(1.4)$ & $66.1(1.4)$ & $52.7(4.7)$ & $85.4(4.8)$ \\
\hline 0.6 & $8.2(0.3)$ & $100(0.3)$ & $81.6(2.0)$ & $51.0(0.8)$ & $226(3)$ & $256(5)$ & $203(4)$ & $274(7)$ & $54.3(1.4)$ & $75.4(2.7)$ & $48.0(1.6)$ & $77.9(3.7)$ \\
\hline 0.7 & $58.8(0.4)$ & $110(0.7)$ & $84.3(3.5)$ & $54.0(0.9)$ & $230(4)$ & $250(4)$ & $217(10)$ & $285(3)$ & $56.2(1.8)$ & $75.0(2.2)$ & $54.2(3.7)$ & $84.3(1.9)$ \\
\hline 0.8 & - & $117(1.5)$ & $85.3(2.1)$ & $57.0(1.1)$ & - & $249(3)$ & $224(6)$ & $290(10)$ & - & $75: 6(1.7)$ & $57.4(2.6)$ & $87.6(5.6)$ \\
\hline 0.9 & $60.5(0.6)$ & $119(0.7)$ & $87.8(2.3)$ & $57.0(1.4)$ & $239(5)$ & $264(3)$ & 239(8) & $300(10)$ & $61.0(2.2)$ & $83.9(1.7)$ & $64.8(4.0)$ & $93.4(6.1)$ \\
\hline 1.0 & $59.8(0.6)$ & $118(1.2)$ & $89.8(2.8)$ & $56.8(1.4)$ & $236(8)$ & $271(4)$ & $230(4)$ & $299(6)$ & $59.6(3.8)$ & $87.2(2.1)$ & $60.8(1.9)$ & $92.8(3.9)$ \\
\hline
\end{tabular}

\footnotetext{
a Standard deviations are shown in parentheses.
} 
TABLE III

\section{EFFECT OF ADDED DEAD VOLUME ON PEAK CHARACTERISTICS}

DuoMonitor Detector at $254 \mathrm{~nm}$

Flow rate $0.5 \mathrm{~mL} / \mathrm{min}$

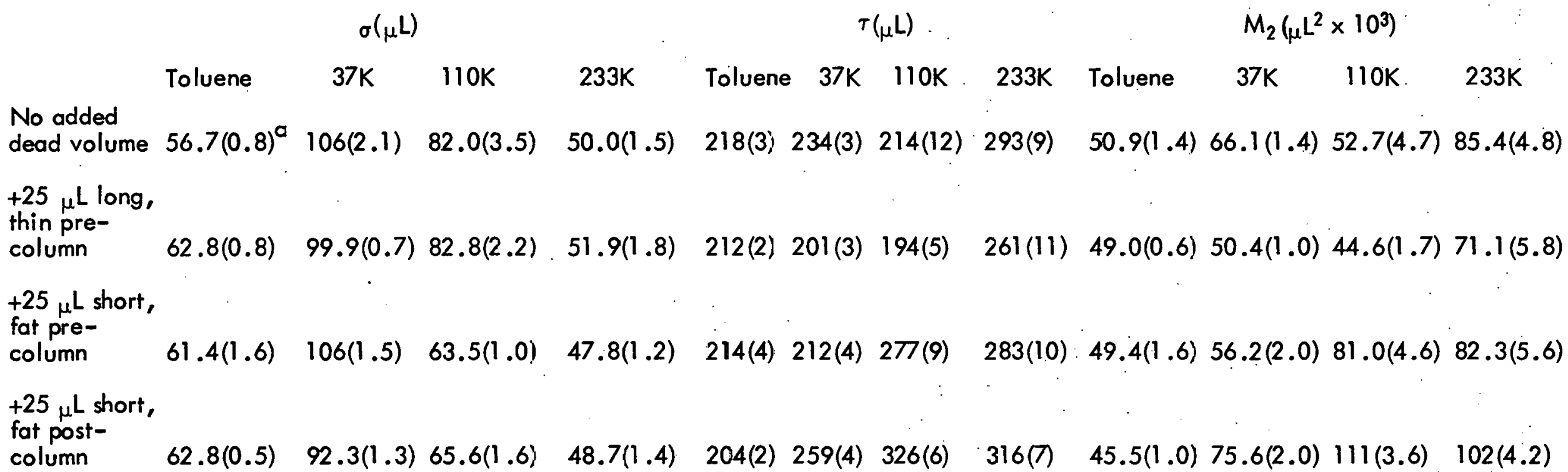

a Standard deviations are shown in parentheses. 
TABLE IV

\begin{tabular}{lccc}
\multicolumn{4}{c}{ DETECTOR DEAD VOLUMES $(\mu . \mathrm{L})$} \\
& Cell & Tubing & Total \\
LDC DuoMonitor & 28 & 10 & 38 \\
PE LC-55 & 10 & 25 & 35 \\
LDC Refractomonitor & 6 & 5 & 11.
\end{tabular}


TABLE $\vee$

EFFECT OF DETECTOR ON PEAK CHARACTERISTICS

Flow Rate $0.5 \mathrm{~mL} / \mathrm{min}$

\begin{tabular}{|c|c|c|c|c|c|c|c|c|c|c|c|}
\hline \multicolumn{4}{|c|}{$\sigma(\mu L)$} & \multicolumn{4}{|c|}{$\tau(\mu \mathrm{L})$} & \multicolumn{4}{|c|}{$M_{2}\left(\mu L^{2} \times 10^{3}\right)$} \\
\hline Tolvene & $37 k$ & $110 \mathrm{~K}$ & $233 \mathrm{~K}$ & Tolvene & $37 \mathrm{~K}$ & $110 \mathrm{~K}$ & $233 K$ & Tolvene & $37 k$ & $110 \mathrm{~K}$ & $233 \mathrm{~K}$ \\
\hline
\end{tabular}

LDC

Duo-

Monitor

$56.7(0.8)^{a} \quad 106(2.1)$

1) $82.0(3.5)$

$50.0(1.5) \quad 218(3) 234(3) 214(12) 293(9)$

$50.9(1.4) 66.1(1.4) 52.7(4.7) 88.6(4.8)$

PE LC -55

$55.3(0.4)$

$81.4(1.5) 65.1(0.6)$

$42.4(0.7) \quad 204(3) \quad 223(7) 217(6)$

$191(6) \quad 44.9(0.6) 56.5(3.0) 51.2(2.4) 38.1(2.4)$

LDC

Refractomonitor

b

$83.8(2.8) \quad 65.1(1.7) \quad 59.9(3.0) \quad$ b $\quad 191(10) 157(12) \quad 157(7) \quad b$

$43.4(3.8) 29.1(3.5) 28.2(2.2)$

\footnotetext{
${ }^{a}$ Standard deviations are shown in parentheses.

beak from solvent in the mobile phase interfered.
} 


$$
d
$$


